\title{
Clinicopathological analysis of recurrence patterns and prognostic factors for survival after hepatectomy for colorectal liver metastasis
}

\author{
Michihiro Hayashi ${ }^{1 *}$, Yoshihiro Inoue ${ }^{1}$, Koji Komeda', Tetsunosuke Shimizu', Mitsuhiro Asakuma', \\ Fumitoshi Hirokawa', Yoshiharu Miyamoto', Junji Okuda', Atsushi Takeshita², Yuro Shibayama², \\ Nobuhiko Tanigawa'
}

\begin{abstract}
Background: Hepatectomy is recommended as the most effective therapy for liver metastasis from colorectal cancer (CRCLM). It is crucial to elucidate the prognostic clinicopathological factors.

Methods: Eighty-three patients undergoing initial hepatectomy for CRCLM were retrospectively analyzed with respect to characteristics of primary colorectal and metastatic hepatic tumors, operation details and prognosis.

Results: The overall 5-year survival rate after initial hepatectomy for CRCLM was 57.5\%, and the median survival time was 25 months. Univariate analysis clarified that the significant prognostic factors for poor survival were depth of primary colorectal cancer ( $\geq$ serosal invasion), hepatic resection margin $(<5 \mathrm{~mm})$, presence of portal vein invasion of CRCLM, and the presence of intra- and extrahepatic recurrence. Multivariate analysis indicated the presence of intra- and extrahepatic recurrence as independent predictive factors for poor prognosis. Risk factors for intrahepatic recurrence were resection margin $(<5 \mathrm{~mm})$ of CRCLM, while no risk factors for extrahepatic recurrence were noted. In the subgroup with synchronous CRCLM, the combination of surgery and adjuvant chemotherapy controlled intrahepatic recurrence and improved the prognosis significantly.

Conclusions: Optimal surgical strategies in conjunction with effective chemotherapeutic regimens need to be established in patients with risk factors for recurrence and poor outcomes as listed above.
\end{abstract}

\section{Background}

Despite recent improvements in the diagnosis and management of colorectal cancer (CRC), which have enabled early detection followed by early treatment, many advanced cases with hepatic or peritoneal metastasis are still encountered. For further improvement of the prognosis of CRC, it is particularly important to prolong the survival of these advanced cases with distant metastasis.

Hepatectomy for liver metastasis from colorectal cancer (CRCLM) is recommended as the most effective therapy [1-11]. However, to date, $50 \%$ to $75 \%$ of patients develop recurrence of the disease after curative resection of CRCLM. Moreover, the cure rate by initial hepatectomy is

\footnotetext{
*Correspondence: sur083@poh.osaka-med.ac.jp

'Department of General and Gastroenterological Surgery, Osaka Medical

College Hospital 2-7 Daigaku-machi, Takatsuki City, Osaka 5698686, Japan

Full list of author information is available at the end of the article
}

only $20 \%$ to $30 \%$ of cases [4-6,12]. Factors associated with recurrence and prognostic determinants after initial hepatectomy are still controversial. Recently, many studies reported that the duration of survival is markedly prolonged by effective chemotherapies, including the molecular target drugs, for unresectable or recurrent colorectal cancer $[13,14]$. Therefore, it is necessary to elucidate predictive factors relevant to recurrence and survival in order to determine optimal treatment strategies for each patient with CRCLM.

The aim of this study was to retrospectively investigate surgical outcomes in a consecutive series of patients undergoing hepatectomy for CRCLM at a single institution, in order to analyze recurrence patterns and clinicopathological prognostic factors for survival. 


\section{Methods \\ Patient selection}

A retrospective study was conducted on 85 consecutive patients undergoing initial hepatectomy for CRCLM for curative intent at Osaka Medical College Hospital from 1995 to 2008. Clinical records and follow-up data were obtained for 83 patients ( 55 men, 28 women). The mean age at the initial hepatectomy was $66.5 \pm 10.4$ years (range, 29-87 years). The mean observation period was 62.8 months (range, 4-129 months). Perioperative mortality was not observed in patients in this study. All patients signed appropriate informed consent for surgical operation and to their inclusion in the study. The current study was approved by the ethics committee of Osaka Medical College Hospital. We also attest that this human study undertaken as part of the research from which this manuscript was derived is in compliance with the Helsinki Declaration.

\section{Characteristics of colorectal cancer}

The primary tumor was in the colon in 60 cases $(72.3 \%)$ and in the rectum in 23 cases (27.7\%). Among patients with CRC, tumors were located in the right colon in 13 (15.7\%), transverse colon in $9(10.8 \%)$, and the left colon in 38 (45.8\%). Sixty-three percent of the primary tumors had involved regional lymph nodes, and $46.8 \%$ and $51.9 \%$ had well- or moderately-differentiated histology, respectively. The histological depth of invasion in the colorectal wall is denoted as follows: se, serosa; ss, subserosa; a1, sub-adventitia; a2, adventitia. In 58 patients (71.6\%), the depth of the primary tumors was within subserosal layer $(\leq$ ss $(\mathrm{a} 1))$ of the colorectal wall.

\section{Hepatectomy}

In this series, hepatectomy was indicated for CRCLM when the following 3 conditions were met: (1) the primary CRC was curatively resected; (2) metastasis located only in the liver; and (3) no limitation regarding the number or size of CRCLM as far as hepatic functional reserve was warranted after hepatectomy. All hepatectomies were performed by three experienced hepatobiliary surgeons ( $\mathrm{MH}, \mathrm{FH}$, and $\mathrm{NT})$ during the study period. All patients received potentially curative hepatectomy with removal of gross tumor with a negative macroscopic margin. With respect to hepatic hilar lymph nodes, lymph node dissection is not routinely performed, since node-positive cases in this region were strongly associated with extremely poor survival in our previous experience (data not shown).

Synchronous (as opposed to metachronous) CRCLM was defined as simultaneous presentation of liver metastasis at the time of CRC operation, and was detected in 28 patients $(33.7 \%)$. They received either synchronous or metachronous hepatectomy, mainly based on the each patient's condition and need.

Generally, partial or non-anatomical hepatectomy was performed, whereas systemic or anatomical hepatectomy was preferred in cases when this procedure had advantage in terms of operation time, blood loss, safety, and invasiveness. Hepatic resection was performed following a standard technique as previously reported [15]. An ultrasonic dissector (SonoSurg system; Olympus Inc., Tokyo, Japan) was used for parenchymal transection, and small vessels were ligated or coagulated using softcoagulation system or bipolar electrocautery. During the resection procedure, surgical margin was carefully confirmed using intraoperative ultrasonography in order to obtain a general surgical margin of 5-10 mm. Thus, in $63.6 \%$ of cases, hepatic surgical margin was wider than or equal to $5 \mathrm{~mm}$.

\section{Chemotherapy}

With respect to chemotherapy before hepatectomy and adjuvant chemotherapy after hepatectomy, the eligibility criteria in this series included histologically-proven adenocarcinoma of the colon or rectum. Patient criteria included an Eastern Cooperative Oncology Group (ECOG) performance status of 0-2. Additionally, patients had to have no serious or uncontrolled concurrent medical illness; no active infection; adequate hematologic parameters $\left(\mathrm{WBC}>4.0 \times 10^{3} / \mathrm{L}\right.$, platelet count $>100 \times 10^{9} / \mathrm{L}$ ), renal functions (serum creatinine $\leq 1.2 \mathrm{mg} / \mathrm{dL}$ or calculated creatinine clearance by Cockroft formula $\geq 50 \mathrm{~mL} / \mathrm{min}$ ), or hepatic functions (total bilirubin $<2.0 \mathrm{mg} / \mathrm{dL}$ and aspartate aminotransferase, alanine aminotransferase $<100 \mathrm{IU} / \mathrm{L})$. Regimens consisted of 5-Fluorouracil (5-FU) alone, 5-FU/leucovorin (LV), 5-FU/cisplatin, tegafur plus uracil (UFT) alone, UFT/LV, oteracil (TS-1), FOLFOX (infusional 5-FU/LV + oxaliplatin), FOLFIRI (infusional 5-FU/LV + irinotecan) and IFL (5-FU/LV + irinotecan). Thus, 35 patients (42.2\%) received chemotherapy before hepatectomy and 56 patients $(71.8 \%)$ received adjuvant chemotherapy after hepatectomy.

\section{Patient follow-up}

Patients were examined for CRCLM recurrence by ultrasonography and contrast enhanced computed tomography (CT) every 4-6 months and blood tests including tumor markers, such as carcinoembryonic antigen (CEA), every 2-3 months after discharge. When recurrence was suspected, magnetic resonance imaging was performed to ensure the appearance of new lesions in the remnant liver, while systemic recurrence was examined by fluorodeoxyglucose-positron emission tomography or Gallium scintigraphy. Chest and pelvic CT was 
also performed principally every 6 months for local and pulmonary metastasis or recurrence. Recurrence was diagnosed when at least two imaging studies confirmed the new lesions showing typical features of CRC/ CRCLM, compared to the previous images. The recurrent CRCLM were treated by repeat hepatectomy when applicable $(n=15)$, otherwise by systemic chemotherapy, or their combination. During the study period, no major changes in clinical aspects were undertaken except for the use of more potent chemotherapeutic agents applied in the recent patients, with other surgical techniques and perioperative patient management being carefully conserved so as to minimize possible bias.

\section{Clinicopathological analysis}

Patient demographics, laboratory tests including tumor markers, tumor characteristics, treatment, recurrence, and survival data were analyzed to determine prognostic factors in terms of 3- and 5-year survival rates after the initial hepatectomy for CRCLM. The surgically resected specimens were studied macro- and microscopically to determine the various tumor characteristics including size of the largest tumor, number of tumors, morphology and extent of the tumor, and surgical margin. For microscopic analysis, the resected specimens were fixed in $10 \%$ formaldehyde and sliced into 5 - $\mathrm{mm}$ sections. After each section was sliced into $5-\mu \mathrm{m}$ tissue sections and stained with hematoxylin and eosin, two specialists of pathology (YS, AT) reviewed for histological confirmation of the pathological diagnosis. In this study, surgical margin status was defined as the distance of the lesion closest to the cut surface of the liver, and macroscopically classified into two categories: a surgical margin of $5 \mathrm{~mm}$ or wider $(\geq 5 \mathrm{~mm})$, and narrower than $5 \mathrm{~mm}(<5 \mathrm{~mm})$.

\section{Statistical analysis}

Actuarial survival rate was calculated by the Kaplan-Meier method. Univariate analyses were performed using the log-rank test. Multivariate analyses were performed by Cox proportional hazards regression. Statistical comparisons were made by Fisher's exact probability test. A difference was regarded as statistically significant at $P<0.05$.

\section{Results}

\section{Primary colorectal tumor characteristics}

Tumor characteristics of primary CRC were analyzed for prognostic values (Table 1). Included were: tumor location (colon or rectum), tumor differentiation (well, moderately, or poorly differentiated adenocarcinoma), number of lymph nodes metastasis, depth of tumor invasion in the colorectal wall ( $\leq$ ss (a1) or $\geq$ se (a2); ss, sub-serosa; se, serosa; a1, sub-adventitia; a2, adventitia), lymphatic invasion, venous invasion, and Duke's stage; the only significant difference in survival rate was observed between patients with primary CRC $\leq$ ss (a1) and those with $\geq$ se (a2) in the colorectal wall $(P=0.0133)$.

\section{Time of liver metastasis and timing of hepatectomy}

Among 83 patients receiving hepatectomy for CRCLM, $13(15.7 \%)$ patients received synchronous liver and colorectal resection, and $70(84.3 \%)$ patients received metachronous resection (Table 1). The 3- and 5-year survival rates were $70.5 \%$ and $70.5 \%$ in 13 patients with synchronous resection, $61.5 \%$ and $55.2 \%$ in 70 patients with metachronous resection. No differences in survival rates between these two groups were noted $(P=0.4927)$.

Synchronous CRCLM was detected at the time of CRC operation in 28 patients (33.7\%). Hepatectomy was done synchronously in 13 and metachronously in 15 patients. The 5 -year survival rate was $70.5 \%$ in 13 patients with synchronous resection, and $54.2 \%$ in 15 patients with metachronous resection. No differences in survival rates between these two groups were noted $(P=0.6547)$. Moreover, timing of hepatectomy was not associated with intra- and extrahepatic recurrence $(P=1.0000)$.

\section{Metastatic liver tumor characteristics}

The mean and the median sizes of the largest metastatic lesions were $3.58 \pm 1.93 \mathrm{~cm}$ and $3.0 \mathrm{~cm}$, respectively. Of 83 patients, 47 patients (56.6\%) underwent resection for solitary metastasis, 27 patients $(32.5 \%)$ for 2 or 3 tumors, and 9 patients $(10.8 \%)$ had 4 or more tumors resected (Table 1$)$. In 63 patients $(75.9 \%)$, the tumor location was unilobar (right in 36, left in 27), and 20 patients $(24.1 \%)$ had bilobar disease resected. There were no significant differences in terms of the number, maximal size, and distribution of CRCLM $(P=0.3868$, 0.9255 , and 0.1882 , respectively). The serum value of CEA immediately before hepatectomy was not associated with subsequent survival rate. Portal vein invasion was observed in 8 patients $(9.8 \%)$ with the significantly worse 3- and 5-year survival when compared with those without portal invasion $(28.6 \%$ and $0 \%$ vs. $66.2 \%$ and $63.4 \%$, respectively, $P=0.0074$; Figure 1 ). However, there was no significant correlation between portal vein invasion and intrahepatic recurrence rate $(P=0.7072)$.

\section{Operation-related parameters}

With regard to the type of hepatectomy (anatomic, 44; non-anatomic, 39) and extent of resection (< lobectomy, $62 ; \geq$ lobectomy, 21 ), no differences in survival rates between these groups were noted $(P=0.4862,0.0875$, respectively, Table 1 ).

Compared with the patients with a hepatic surgical margin $\geq 5 \mathrm{~mm}(\mathrm{n}=49,63.6 \%)$, the 3 - and 5-year survival rates for those with resection margin $<5 \mathrm{~mm}(\mathrm{n}=28$, 
Table 1 Analysis of clinicopathological factors for prognosis

\begin{tabular}{|c|c|c|c|c|c|}
\hline Factor & $\begin{array}{l}\text { Number of } \\
\text { patients }\end{array}$ & $\begin{array}{c}\text { 3-year survival rate } \\
(\%)\end{array}$ & $\begin{array}{c}\text { 5-year survival rate } \\
(\%)\end{array}$ & $\begin{array}{c}\text { Univariate } \\
P \text {-value }\end{array}$ & $\begin{array}{c}\text { Multivariate } \\
P \text {-value }\end{array}$ \\
\hline Sex & & & & 0.9217 & \\
\hline Male & 55 & 61.1 & 57.0 & & \\
\hline Female & 28 & 65.9 & 58.6 & & \\
\hline \multicolumn{6}{|l|}{ Location of CRC } \\
\hline Rt-hemicolon & 13 & 38.1 & 38.1 & & \\
\hline Transverse colon & 9 & 75.0 & 56.3 & & \\
\hline Lt-hemicolon & 38 & 58.8 & 53.9 & & \\
\hline Any colon & 60 & 57.0 & 50.7 & 0.0794 & \\
\hline Rectum & 23 & 81.3 & 81.3 & & \\
\hline Depth of CRC & & & & 0.0133 & 0.3183 \\
\hline$<$ ss (a1) & 58 & 70.0 & 66.5 & & \\
\hline$\geq$ se $(\mathrm{a} 2)$ & 23 & 47.3 & 39.4 & & \\
\hline Tumor differentiation of CRC & & & & 0.4712 & \\
\hline Well & 37 & 70.4 & 65.0 & & \\
\hline Moderate & 41 & 53.3 & 48.0 & & \\
\hline Poor & 1 & 100.0 & 100.0 & & \\
\hline Lymphatic invasion of CRC & & & & 0.7469 & \\
\hline Present & 66 & 62.6 & 62.6 & & \\
\hline Absent & 14 & 73.5 & 45.9 & & \\
\hline Venous invasion of CRC & & & & 0.4259 & \\
\hline Present & 63 & 67.2 & 64.2 & & \\
\hline Absent & 18 & 55.6 & 41.7 & & \\
\hline Lymph node metastasis of CRC & & & & 0.6040 & \\
\hline 0 & 30 & 70.9 & 57.8 & & \\
\hline $1 \sim 3$ & 39 & 64.0 & 64.0 & & \\
\hline$\geq 4$ & 13 & 48.4 & 48.4 & & \\
\hline Present & 52 & 59.7 & 59.7 & 0.6779 & \\
\hline Absent & 30 & 70.9 & 57.8 & & \\
\hline Duke's stage of CRC & & & & 0.4376 & \\
\hline A & 7 & 80.0 & 80.0 & & \\
\hline B & 11 & 60.6 & 22.7 & & \\
\hline C & 33 & 60.2 & 60.2 & & \\
\hline $\mathrm{D}$ & 30 & 65.0 & 65.0 & & \\
\hline Age at hepatectomy & & & & 0.5150 & \\
\hline$<50$ years & 6 & 66.7 & 66.7 & & \\
\hline$\geq 50$ years & 77 & 64.5 & 57.0 & & \\
\hline CEA before hepatectomy & & & & 0.2441 & \\
\hline$<5 \mathrm{ng} / \mathrm{ml}$ & 27 & 53.9 & 49.4 & & \\
\hline$\geq 5 \mathrm{ng} / \mathrm{ml}$ & 54 & 68.7 & 62.4 & & \\
\hline Time of liver metastasis & & & & 0.7865 & \\
\hline Synchronous & 28 & 61.2 & 61.2 & & \\
\hline Metachronous & 55 & 63.7 & 56.8 & & \\
\hline Timing of hepatectomy & & & & 0.4927 & \\
\hline Synchronous & 13 & 70.5 & 70.5 & & \\
\hline Metachronous & 70 & 61.5 & 55.2 & & \\
\hline Method of hepatectomy & & & & 0.4862 & \\
\hline Anatomical & 44 & 62.1 & 55.9 & & \\
\hline Non-anatomical & 39 & 63.2 & 59.0 & & \\
\hline
\end{tabular}


Table 1 Analysis of clinicopathological factors for prognosis (Continued)

\begin{tabular}{|c|c|c|c|c|c|}
\hline \multicolumn{4}{|l|}{ Extent of hepatectomy } & \multicolumn{2}{|l|}{0.0875} \\
\hline$<$ Lobectomy & 62 & 67.1 & 63.8 & & \\
\hline$\geq$ Lobectomy & 21 & 46.5 & 31.0 & & \\
\hline Number of CRCLM & & & & 0.3868 & \\
\hline Solitary & 47 & 69.3 & 61.0 & & \\
\hline Multiple & 36 & 51.8 & 51.8 & & \\
\hline Location of CRCLM & & & & 0.1882 & \\
\hline Unilobar & 63 & 68.9 & 62.6 & & \\
\hline Bilobar & 20 & 32.2 & 32.2 & & \\
\hline Size of CRCLM & & & & 0.9254 & \\
\hline$<3 \mathrm{~cm}$ & 42 & 71.3 & 62.9 & & \\
\hline $3-5 \mathrm{~cm}$ & 26 & 51.8 & 51.8 & & \\
\hline$\geq 5 \mathrm{~cm}$ & 14 & 50.4 & 50.4 & & \\
\hline Resection margin of CRCLM & & & & 0.0399 & 0.3917 \\
\hline$<5 \mathrm{~mm}$ & 28 & 47.8 & 41.8 & & \\
\hline$\geq 5 \mathrm{~mm}$ & 49 & 70.4 & 64.5 & & \\
\hline Portal vein invasion of CRCLM & & & & 0.0074 & 0.2689 \\
\hline Present & 8 & 28.6 & 0 & & \\
\hline Absent & 74 & 66.2 & 63.4 & & \\
\hline Intrahepatic recurrence & & & & 0.0104 & 0.0051 \\
\hline Present & 32 & 44.6 & 32.5 & & \\
\hline Absent & 46 & 75.1 & 75.1 & & \\
\hline Extrahepatic recurrence & & & & 0.0217 & 0.0064 \\
\hline Present & 26 & 43.1 & 43.1 & & \\
\hline Absent & 54 & 69.4 & 63.0 & & \\
\hline Lung recurrence & & & & 0.1349 & \\
\hline Present & 18 & 39.9 & - & & \\
\hline Absent & 62 & 66.1 & 60.3 & & \\
\hline $\begin{array}{l}\text { Chemotherapy before } \\
\text { hepatectomy }\end{array}$ & & & & 0.0991 & \\
\hline Present & 35 & 51.1 & 43.8 & & \\
\hline Absent & 48 & 72.7 & 68.6 & & \\
\hline Chemotherapy after hepatectomy & & & & 0.3617 & \\
\hline Present & 56 & 63.6 & 60.3 & & \\
\hline Absent & 22 & 52.8 & 45.2 & & \\
\hline
\end{tabular}

CRC: colorectal cancer, CRCLM: liver metastasis from colorectal cancer, CEA: carcinoembryonic antigen.

$36.4 \%)$ were significantly worse ( $\geq 5 \mathrm{~mm}$ vs. $<5 \mathrm{~mm}$, $70.4 \%$ and $64.5 \%$ vs. $47.8 \%$ and $41.8 \%$, respectively $P=$ 0.0399; Figure 2). During hepatic parenchymal resection, tumors were exposed on the cut surface of the liver in 6 patients $(7.3 \%)$; however, the survival of those patients was not significantly different from the other patients without tumor exposure.

Intra- and extrahepatic recurrence after initial hepatectomy

Recurrence was detected in $52(65.0 \%)$ of the patients who underwent hepatectomy (Table 1). The site of the first recurrence was the liver in $32(41.0 \%)$ patients. Twenty-six (32.5\%) patients had extrahepatic recurrence; the lung in 18 , the peritoneal cavity or local recurrence in 9 , the brain in 2 , and the bone in 1 . Patients with recurrent hepatic metastasis after initial hepatectomy $(n=37$, $44.6 \%$ ) had a significantly worse survival than those without hepatic recurrence $(\mathrm{n}=46,55.4 \%, P=0.0104)$. Moreover, patients with recurrent extrahepatic metastasis after initial hepatectomy had a significantly worse survival than those without extrahepatic recurrence $(P=0.0217)$. Especially, those with lung metastasis after hepatectomy had extremely poor survival (3 years, 39.9\%; 5 years, $0 \%$ ).

Risk factors for intra- and extrahepatic recurrence were analyzed. On uni- and multivariate analysis, hepatic resection margin $(<5 \mathrm{~mm})$ was significantly associated with intrahepatic recurrence after initial hepatectomy 


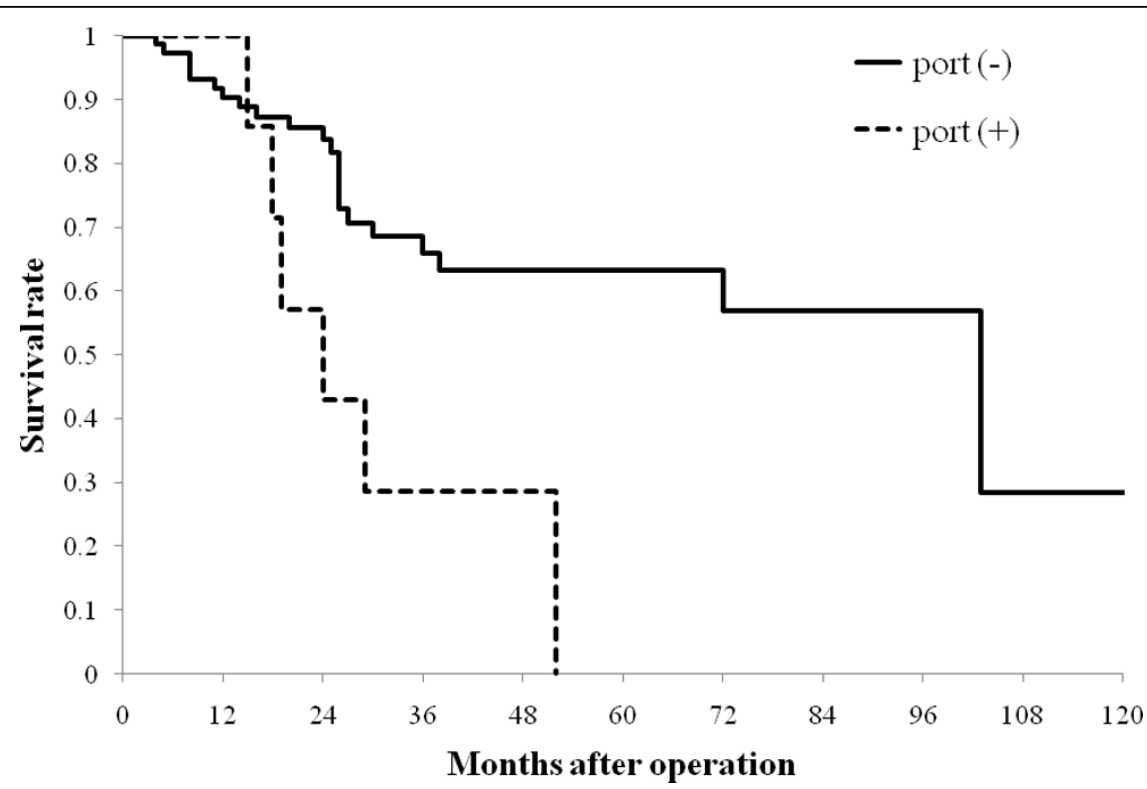

Figure 1 Survival curves according to portal vein invasion in the resected liver specimen. No portal vein invasive disease is denoted as "port $(-)$ ". Invasion confined to the portal vein is arbitrarily designated as "port (+)". Portal vein invasion was observed in 8 patients with the significant worse 3- and 5 year survival when compared with those without portal invasion ( $28.6 \%$ and $0 \%$ vs. $66.2 \%$ and $63.4 \%$, respectively, $P=0.0074$ ).

$(P=0.0133 ;$ Table 2). No significant risk factors for extrahepatic recurrence were identified (data not shown).

\section{Perioperative chemotherapy}

Thirty-five patients (42.2\%) received chemotherapy before initial hepatectomy, and 56 patients $(71.8 \%)$ received chemotherapy after hepatectomy. Overall, the presence or absence of chemotherapy, regardless of chemotherapy before or after hepatectomy, or the combination, was not associated with intra- or extrahepatic recurrence or survival (Tables 1,2). In subgroup analysis, in 55 patients with metachronous CRCLM, chemotherapy before and/or after hepatectomy was not associated with recurrence or the prognosis (Tables 3,4 ). On the contrary, in 28 patients

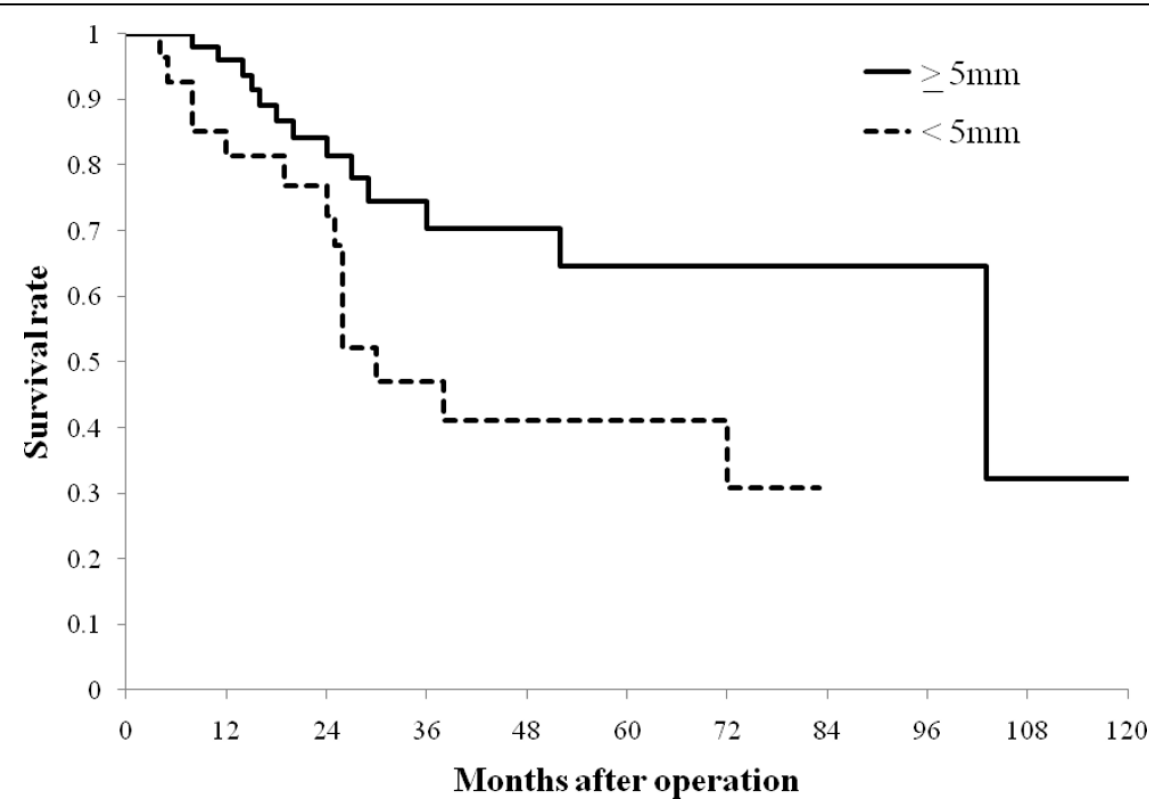

Figure 2 Survival curves according to surgical margin in the resected liver specimen. A surgical margin of $5 \mathrm{~mm}$ or wider is denoted as " $\geq 5 \mathrm{~mm}$ ". A surgical margin narrower than $5 \mathrm{~mm}$ is denoted as " $<5 \mathrm{~mm}$ ". Patients with a surgical margin of $5 \mathrm{~mm}$ or wider had a better survival rate than those with a narrower resection margin $(P=0.0399)$. 
Table 2 Risk factors for intrahepatic recurrence after initial hepatectomy

\begin{tabular}{|c|c|c|c|}
\hline Factor & Number of patients & Univariate $P$-value & Multivariate $P$-value \\
\hline Location of CRC & & 0.0733 & \\
\hline Colon & 27 & & \\
\hline Rectum & 5 & & \\
\hline Depth of CRC & & 0.2112 & \\
\hline$<\mathrm{ss}(\mathrm{a} 1)$ & 19 & & \\
\hline$>$ se $(\mathrm{a} 2)$ & 12 & & \\
\hline Tumor differentiation of CRC & & 0.4618 & \\
\hline well & 13 & & \\
\hline moderate & 16 & & \\
\hline poor & 1 & & \\
\hline Lymphatic invasion of CRC & & 1.0000 & \\
\hline Present & 25 & & \\
\hline Absent & 5 & & \\
\hline Venous invasion of CRC & & 0.7765 & \\
\hline Present & 23 & & \\
\hline Absent & 7 & & \\
\hline Lymph node metastasis of CRC & & 0.6320 & \\
\hline Present & 21 & & \\
\hline Absent & 10 & & \\
\hline Time of liver metastasis & & 0.8151 & \\
\hline Synchronous & 12 & & \\
\hline Metachronous & 20 & & \\
\hline Timing of hepatectomy & & 1.0000 & \\
\hline Synchronous & 6 & & \\
\hline Metachronous & 26 & & \\
\hline Number of CRCLM & & 0.3516 & \\
\hline Single & 16 & & \\
\hline Multiple & 16 & & \\
\hline Size of CRCLM & & 0.1218 & \\
\hline$<5 \mathrm{~cm}$ & 23 & & \\
\hline$\geq 5 \mathrm{~cm}$ & 8 & & \\
\hline Portal vein invasion of CRCLM & & 0.7072 & \\
\hline Present & 4 & & \\
\hline Absent & 27 & & \\
\hline Surgical margin of CRCLM & & 0.0228 & 0.0133 \\
\hline$<5 \mathrm{~mm}$ & 15 & & \\
\hline$\geq 5 \mathrm{~mm}$ & 13 & & \\
\hline Chemotherapy before hepatectomy & & 0.4837 & \\
\hline Present & 15 & & \\
\hline Absent & 17 & & \\
\hline Chemotherapy after hepatectomy & & 0.1976 & \\
\hline Present & 19 & & \\
\hline Absent & 12 & & \\
\hline
\end{tabular}

CRC: colorectal cancer, CRCLM: liver metastasis from colorectal cancer.

with synchronous CRCLM, adjuvant chemotherapy after hepatectomy was significantly associated with lower intrahepatic recurrence rate $(P=0.0087)$ and better prognosis $(P=0.0458)$ after initial hepatectomy, but not for extrahepatic recurrence (Tables 5,6 ).
Patient survival and prognostic factors

The survival time ranged from 4 months to 129 months, mean survival time was $36.5+28$ months, and median survival time was 25 months. The 5 -year survival rate for the 83 patients after initial hepatectomy was $57.5 \%$, 
Table 3 Effect of peri-operative chemotherapy on survival for metachronous CRCLM

\begin{tabular}{ccccc}
\hline & Number of patients & 3-year survival rate (\%) & 5-year survival rate (\%) & Univariate $\boldsymbol{P}$-value \\
\hline $\begin{array}{c}\text { Chemotherapy before hepatectomy } \\
\text { Present }\end{array}$ & 32 & 53.2 & 45.6 & 0.1872 \\
Absent & 23 & 80.0 & 72.8 & \\
\hline $\begin{array}{c}\text { Chemotherapy after hepatectomy } \\
\text { Present }\end{array}$ & 36 & & & 53.1 \\
Absent & 15 & 57.9 & 61.9 & 0.7919 \\
\hline
\end{tabular}

which is comparable to reported survival rates of $20 \%$ to $58 \%$ [4,6-8,10-12,16,17]. Prognostic factors analyzed are shown in Table 1. On univariate analysis, tumor depth of CRC ( $\leq$ ss (a1) vs. $\geq$ se (a2)), portal vein invasion of CRCLM, macroscopic hepatic resection margin $(<5$ $\mathrm{mm}$ vs. $\geq 5 \mathrm{~mm}$ ), and the presence of intra- and extrahepatic recurrence were associated with a significant difference in survival rate after initial hepatectomy $(P=$ $0.0133,0.0074,0.0399,0.0104$, and 0.0217 , respectively, Table 1, Figure 3). Multivariate analysis revealed that independent prognostic factors for poor outcome were the presence of intra- and/or extrahepatic recurrence $(P=0.0051,0.0064$, respectively, Table 1$)$.

\section{Discussion}

While untreated CRCLM has a poor prognosis with median survival ranging from 6 to 12 months and is not expected to be over 5 years, long-term survival and potential for cure following surgical resection for CRCLM had been demonstrated in numerous uncontrolled studies $[7,8,12]$. These studies reported that the overall 5-year survival rates are in the range of $20 \%$ to $58 \%$, and the median survival times are 24-46 months [4,6-8,10-12,16,17]. However, it has also been reported that $57 \%$ to $78 \%$ of those patients will develop a recurrence of the disease in the hepatectomy series, and intrahepatic recurrence occurs in approximately $50 \%$ of patients $[4,6,9,18]$. It has been considered that occult metastasis surfacing from the primary CRC and residual lesion scattered from liver metastasis are the two major pathways through which hepatic recurrence of metastatic lesion occurs after initial hepatectomy $[19,20]$. Therefore, treatment strategies including hepatic resection should be determined on the basis of these mechanisms for recurrence of metastasis. In Japan, surgical procedures for CRCLM are recommended if the following conditions are met: (1), the primary tumor was curatively resected; (2), metastasis is located only in the liver; (3), the patient is in a condition to be able to bear hepatectomy; and relative indications include: (4), extrahepatic metastasis can be controlled when present; and (5), reductive operation is a part of multimodal treatment [21]. However, the detailed consensus in terms of ideal timing, type, and extent of hepatectomy and optimal combination with perioperative chemotherapy are not currently provided with sufficient evidence. The aims of this study are to retrospectively evaluate the significant prognostic factors for survival and risk factors for recurrence in patients who underwent hepatectomy, and thereby to determine the optimal timing and method of hepatectomy with concurrent use of perioperative chemotherapy.

In the present study, prognostic factors on univariate analysis were the depth of the primary CRC, portal vein invasion and surgical margin at hepatectomy for CRCLM, and the presence of intra- and extrahepatic recurrence after the initial hepatectomy. Independent prognostic factors on multivariate analysis were the presence of intra- and extrahepatic recurrence. Of these factors, the portal vein invasion and surgical margin status at hepatectomy are important factors through which surgery can improve prognosis.

There have been several reports on the risk factors of intra- and extrahepatic recurrence [7,22-24]. In the present study, an independent risk factor for intrahepatic recurrence was the hepatic resection margin, while there were no risk factors regarding extrahepatic recurrence. Hematogenous dissemination of CRC was reported to be significantly associated with the size of liver metastatic nodules by the cascade theory [25]. In this theory,

Table 4 Effect of peri-operative chemotherapy on recurrence for metachronous CRCLM

\begin{tabular}{|c|c|c|c|c|c|c|c|}
\hline & & Intrahepatic rec & & $P$-value & Extrahepatic recurrence & & $P$-value \\
\hline & & Present & Absent & & Present & Absent & \\
\hline \multirow[t]{2}{*}{ Chemotherapy before hepatectomy } & Present & 12 & 17 & 1.0000 & 13 & 18 & 0.2394 \\
\hline & Absent & 8 & 13 & & 5 & 16 & \\
\hline \multirow[t]{2}{*}{ Chemotherapy after hepatectomy } & Present & 14 & 19 & 1.0000 & 13 & 22 & 0.5335 \\
\hline & Absent & 6 & 9 & & 4 & 11 & \\
\hline
\end{tabular}


Table 5 Effect of peri-operative chemotherapy on survival for metachronous synchronous CRCLM

\begin{tabular}{ccccc}
\hline & Number of patients & 3-year survival rate (\%) & 5-year survival rate (\%) & Univariate $\boldsymbol{P}$-value \\
\hline $\begin{array}{c}\text { Chemotherapy before hepatectomy } \\
\text { Present }\end{array}$ & 3 & 33.3 & 0 & 0.2267 \\
Absent & 25 & 66.0 & 66.0 & \\
\hline $\begin{array}{c}\text { Chemotherapy after hepatectomy } \\
\text { Present }\end{array}$ & 20 & & & \\
Absent & 7 & 0 & 0.5 & 0.0458 \\
\hline
\end{tabular}

in accordance with the process of CRCLM metastasizing to the lung and subsequently to the other organs, the size of CRCLM is thought to increase. However, the present study did not include the size or the number of CRCLM as risk factors for intra- or extrahepatic recurrence, implicating the significance of surfacing micrometastasis from the primary CRC which could not be detected perioperatively.

The surgical margin of $<5 \mathrm{~mm}$ at hepatectomy was detected as a risk factor for subsequent intrahepatic metastasis in this study. The role of surgical margin status as a prognostic factor to predict posthepatectomy survival has been controversial [24,26-29], and in the largest single-center series, Are et al. reported that a margin width $>1 \mathrm{~cm}$ was an independent predictor for better survival and is optimal [28]. Nuzzo et al. also recently reported that a histological surgical margin of $\leq$ $5 \mathrm{~mm}$ was associated with lower overall and disease-free survival rates independent of other clinic-pathologic factors [29]. In contrast, Bodingbauer et al. demonstrated that the rate of recurrence at the surgical margin was low and a positive margin was not associated with an increased risk of recurrence either at the surgical margin or elsewhere, if hepatectomy was performed with ultrasonic dissector by experienced surgeons [24]. The present study is distinct from previous studies because macroscopic, instead of histological, surgical margin utilized as a parameter. A macroscopic surgical margin rather than microscopic margin was adopted, since 1) use of various dissection and coagulation devices, such as soft-coagulation system, ultrasonic dissector, and bipolar electrocautery during hepatic parenchymal transection [15], would potentially hinder an accurate assessment regarding pathological surgical margin status including R0 (no residual tumor) and R1 (microscopic residual tumor) status [24,29]; and 2) the macroscopic surgical margin was considered a better parameter of clinical usefulness for patient and treatment selection. Namely, during preoperative evaluation, whether a surgical margin of $\geq 5 \mathrm{~mm}$ was macroscopically feasible or not, it was utilized as a practical marker to determine which was indicated first as an initial therapy for each patient: hepatectomy or neoadjuvant chemotherapy. If the surgical margin was estimated to be $<5 \mathrm{~mm}$, preoperative chemotherapy is the best option [30]. It does need to be noted that resection should not be precluded whatever the width of the surgical margin, since no other single treatment modality can surpass hepatectomy even with a 0 - to $1-\mathrm{cm}$ surgical margin [28]. In the present study, surgical margin status was determined as a prognostic factor on univariate, but not on multivariate analysis. These findings are in accordance with the report by Kokudo et al. that found the surgical margin was correlated with tumor recurrence but not with survival rate [26]. However, when an insufficient surgical margin is suspected during hepatectomy, or postoperative pathology of the resected specimen reveals inadequate surgical margin, adjuvant chemotherapy should be started to prevent intrahepatic recurrence, though a prospective study on this approach is necessary to make definite conclusions.

Portal vein invasion in the resected liver was observed in a small number of patients (9.8\%), but also showed significant negative impact on survival, suggesting it could reflect the grade of aggressiveness and invasiveness of each tumor or the potential for intrahepatic micrometastases, as has been implicated by some authors [29,31] in the context of surgical margin status as a surrogate marker for malignant potential. Therefore, optimal surgery should include a strategy against portal vein

Table 6 Effect of peri-operative chemotherapy on recurrence for synchronous CRCLM

\begin{tabular}{|c|c|c|c|c|c|c|c|}
\hline & & Intrahepatic rec & & $P$-value & Extrahepatic recurrence & & $P$-value \\
\hline & & Present & Absent & & Present & Absent & \\
\hline \multirow[t]{2}{*}{ Chemotherapy before hepatectomy } & Present & 3 & 0 & 0.0672 & 0 & 3 & 0.5360 \\
\hline & Absent & 9 & 16 & & 8 & 17 & \\
\hline \multirow[t]{2}{*}{ Chemotherapy after hepatectomy } & Present & 5 & 15 & 0.0087 & 8 & 12 & 0.0681 \\
\hline & Absent & 6 & 1 & & 0 & 7 & \\
\hline
\end{tabular}




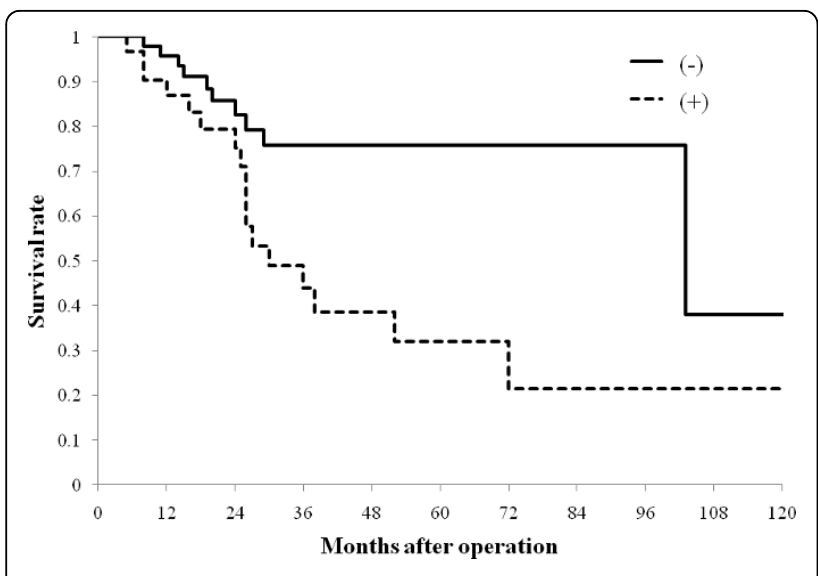

Figure 3 Survival curves according to the presence of intrahepatic recurrence after the initial hepatectomy. The presence of recurrence is denoted as "(+)" and absence " $(-)^{\prime \prime}$. The presence of intrahepatic recurrence were associated with a significant difference in survival after initial hepatectomy $(P=$ 0.0104).

invasion, such as anatomical hepatic resection including Glisson's sheath with a sufficient margin, and aggressive adjuvant chemotherapy for this subgroup of patients [32]. Further studies are needed to clarify its clinical significance.

Regarding the timing of hepatectomy for synchronous CRCLM, controversy remains on whether to perform simultaneous resection or to include an observation period for a couple of months. No differences between these two approaches were detected in the present study, suggesting that in synchronous situations, surgery should be planned at least before hepatic tumor(s)

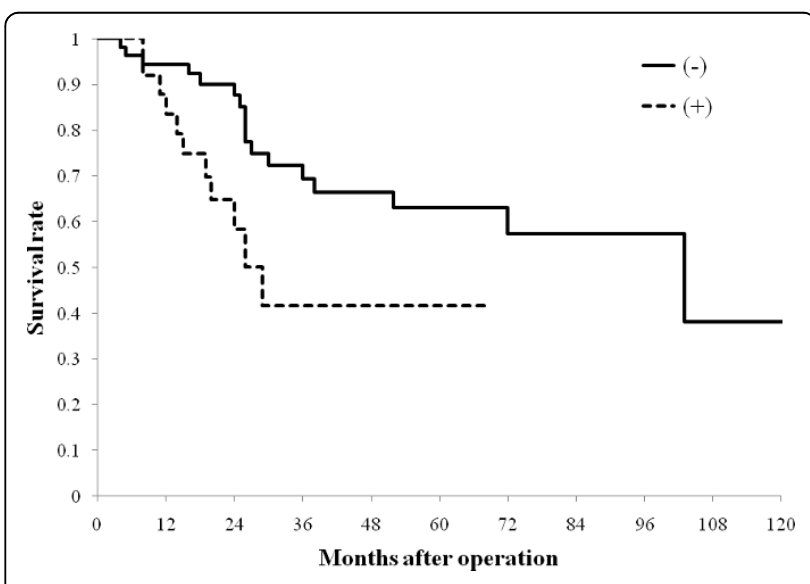

Figure 4 Survival curves according to the presence of extrahepatic recurrence after the initial hepatectomy. The presence of recurrence is denoted as " $(+)^{\prime \prime}$ and absence " $(-)$ ". The presence of extrahepatic recurrence were associated with a significant difference in survival after initial hepatectomy $(P=0.0217)$. become unresectable and that patients need to be treated with adjuvant chemotherapy immediately, since this subgroup appeared to benefit from adjuvant chemotherapy.

A further point of concern is multiple bilobar CRCLM lesions which precipitate the most challenging situation for hepatic surgeons. Although some portion of this patient cohort would indeed benefit from aggressive chemotherapy and subsequent hepatectomy after successful down-sizing of those lesions, many of these patients are not candidates for surgical intervention. Appropriate application and adequate combination of modalities, such as radiofrequency ablation [33], percutaneous transhepatic portal embolization [34], and twostage hepatectomy are expected to extend the surgical indication for these patients [35].

There is not yet a sufficient consensus as to whether the perioperative chemotherapy is significantly associated with disease-free survival or prognosis [36]. In the present report, a combination of surgical therapy and adjuvant chemotherapy after hepatectomy controlled intrahepatic recurrence and consequently improved the prognosis significantly, but only in the subgroup with synchronous CRCLM. Conversely, in the patient subgroup with synchronous CRCLM, adjuvant chemotherapy would be essential. As for metachronous disease, no benefits from chemotherapy were detected in this study. However, it should be noted that the chemotherapy in the present series mainly depended on UFT + LV, TS-1, FOLFOX and FOLFIRI, and the recently developed molecular targeting agents, such as bevacizumab and cetuximab, which have been reported to improve the prognosis of recurrent and unresectable CRC [14,37-39], were not included in this study. Since use of these newer chemotherapeutic agents before hepatectomy is expected to control recurrence by extermination of the micro cancer cell, a similar study is currently being conducted on those patients who received these newer chemotherapeutic agents.

\section{Conclusions}

In CRCLM, intra- and extrahepatic recurrence were independent prognostic factors, and independent risk factors for intrahepatic recurrence included macroscopic resection margin during hepatectomy. Combination of surgery and adjuvant chemotherapy for synchronous CRCLM could control intrahepatic recurrence and significantly improve prognosis. Considering the outcomes of treatment for CRCLM are not yet satisfying, extermination of the micro cancer cell should be achieved by introduction of more potent chemotherapeutic agents in combination with optimal surgery. Further studies are needed to clarify this matter. 


\section{Author details}

'Department of General and Gastroenterological Surgery, Osaka Medical College Hospital 2-7 Daigaku-machi, Takatsuki City, Osaka 5698686, Japan. ${ }^{2}$ Department of Pathology, Osaka Medical College Hospital 2-7 Daigakumachi, Takatsuki City, Osaka 5698686, Japan.

\section{Authors' contributions}

$\mathrm{MH}$ conceived the study concept and design, was involved with patient care and drafted the manuscript and literature review. YI, KK, TS, MA, FH, YM, JO, AT, and YS were involved with formation of the study concept and design, patient care and drafting of the manuscript and literature review. NT carried out the operation on the patient and was the main contributor in the writing of the manuscript. All authors have read and approved the final version of the manuscript. Please see sample text in the instructions for authors.

\section{Competing interests}

The authors declare that they have no competing interests.

Received: 20 May 2010 Accepted: 27 September 2010 Published: 27 September 2010

\section{References}

1. Adson MA: Resection of liver metastasis - When is it worthwhile? World J Surg 1987, 11:511-520.

2. Fortner JG: Recurrence of colorectal cancer after hepatic resection. Am J Surg 1988, 155:378-382.

3. Scheele J, Stangl R, Altendorf-Hofmann A, Gall FP: Indicators of prognosis after hepatic resection for colorectal secondaries. Surgery 1991, 110:13-29.

4. Yokoi Y, Suzuki S, Nakamura S: The impact of hepatic resection on metastatic colorectal cancer. Jpn J Cancer Chemother 2002, 29:848-855, (In Japanese with English abstract).

5. Suzuki S, Sakaguchi T, Yokoi Y, Kurachi K, Okamoto K, Okumura T, Tsuchiya Y, Nakamura T, Konno H, Baba S, Nakamura S: Impact of repeat hepatectomy on recurrent colorectal liver metastases. Surgery 2001, 129:421-428.

6. Nakamura S, Suzuki S, Konno H: Resection of hepatic metastases of colorectal carcinoma: 20 year' experience. J Hep Bil Pancr Surg 1999, 1:16-22.

7. Choti MA, Sitzmann JV, Tiburi MF, Sumetchotimetha W, Rangsin R, Schulicl RD, Lillemoe KD, Yeo CJ, Cameron JL: Trends in long-term survival following liver resection for hepatic colorectal metastases. Ann Surg 2002, 235:759-766

8. Fong Y, Fortner J, Sun RL, Brennan MF, Blumgart LH: Clinical score for predicting recurrence after hepatic resection for metastatic colorectal cancer: analysis of 1001 consecutive cases. Ann Surg 1999, 230:309-318.

9. Assumpcao L, Choti MA, Gleisner AL, Schulick RD, Swartz M, Herman J, Gearhart SL, Pawlik TM: Patterns of recurrence following liver resection for colorectal metastases. Arch Surg 2008, 143:743-749.

10. Nordinger B, Parc R, Delva E, Quilinchini MA, Hannoun L, Huguet C: Hepatic resection for colorectal liver metastases. Influence on survival of preoperative factors and surgery for recurrence. 80 cases. Ann Surg 1989, 205:256-263.

11. Koike M, Yasui K, Torii A, Kodama S: Prognostic significance of entrapped liver cells in hepatic metastases from colorectal cancer. Ann Surg 2000, 232:653-657.

12. Pawlik TM, Schlick RD, Choti MA: Expanding criteria for resectability of colorectal liver metastases. Oncologist 2008, 13:51-64.

13. Tournigand C, Andre T, Achille E, Lledo G, Flesh M, Mery-Mignard D, Quinaux E, Couteau C, Buyse M, Ganem G, Landi B, Colin P, Louvet C, de Gramont A: FOLFIRI followed by FOLFOX6 or the reverse sequence in advanced colorectal cancer: a randomized GERCOR study. J Clin Oncol 2004, 22:229-237.

14. NCCN Clinical Practice Guidelines in Oncology Colon Cancer, V2, 2009. [http://www.nccn.org], [Accessed November 20 2009].

15. Hirokawa F, Hayashi M, Miyamoto $Y$, Iwamoto M, Tsunematsu I, Asakuma M, Shimizu T, Komeda K, Inoue Y, Tanigawa N: A novel method using the $\mathrm{VIO}^{\mathrm{TM}}$ soft-coagulation system for liver. Surgery 2010.

16. Tomlinson JS, Jarnagin WR, DeMatteo RP, Fong Y, Kornprat P, Gonen M, Kemeny N, Brennan MF, Blumgart LH, D'Angelica M: Actual 10-year survival after resection of colorectal liver metastases defines cure. J Clin Oncol 2007, 25:4575-4580.

17. Yamamoto J, Shimada K, Kosuge T, Yamasaki S, Sakamoto M, Fukuda H: Factors influencing survival of patients undergoing hepatectomy for colorectal metastases. Br J Surg 1999, 86:332-337.

18. Malafosse R, Penna Ch, Cunha AS, Nordlinger B: Surgical management of hepatic metastases from colorectal malignancies. Ann Oncol 2001, 12:887-894.

19. Tanaka K, Togo S, Ota M, Fujii Y, Nagano Y, Endo I, Sekido H, Shimada H: Suitable hepatectomy procedure for the liver metastasis of colorectal cancer. Jpn J Gastroentero/ Surg 2001, 34:1289-1294, (In Japanese with English abstract)

20. Shimada H, Nanko M, Fujii S, Masui H, Togo S, Ike H, Nakano A, Ohki S: Treatment strategies for hepatic metastasis from colorectal cancer. $J$ Hepatobiliary pancreat Surg 1995, 2:116-121.

21. Japanese Society for Cancer of the Colon and Rectum: Japanese classification of colorectal carcinoma second English edition. 2009.

22. Yokoyama N, Shirai $Y$, Ajioka $Y$, Nagakura S, Suda T, Hatakeyama K: Immunohistochemically detected hepatic micrometastases predict a high risk of intrahepatic recurrence after resection of colorectal carcinoma liver metastases. Cancer 2002, 94:1642-1647.

23. Ueno $\mathrm{H}$, Mochizuki $\mathrm{H}$, Hashiguchi $\mathrm{Y}$, Hatsuse $\mathrm{K}$, Fujimoto $\mathrm{H}$, Hase $\mathrm{K}$ : Predictors of extrahepatic recurrence after resection of colorectal liver metastases. Br J Surg 2004, 91:327-333.

24. Bodingbauer M, Tamandl D, Schmid K, Plank C, Schima W, Gruenberger T: Size of surgical margin does not influence recurrence rates after curative liver resection for colorectal cancer liver metastases. $\mathrm{Br}$ J Surg 2007, 94:1133-1138.

25. Weiss L, Grundmann E, Torhorst J, Hartveit F, Moberg I, Eder M, FenoglioPreiser CM, Napier J, Horne CH, Lopez MJ, et al: Haematogenous metastatic patterns in colonic carcinoma: an analysis of 1541 necropsies. J Pathol 1986, 150:195-201.

26. Kokudo N, Miki Y, Sugai S, Yanagisawa A, Kato Y, Sakamoto Y, Yamamoto J, Yamaguchi T, Muto T, Makuuchi M: Genetic and histological assessment of surgical margins in resected liver metastases from colorectal carcinoma: minimum surgical margins for successful resection. Arch Surg 2002, 137:833-840

27. Pawlik TM, Scoggins CR, Zorzi D, Abdalla EK, Andres A, Eng C, Curley SA Loyer EM, Muratore A, Mentha G, Capussotti L, Vauthey JN: Effect of surgical margin status on survival and site of recurrence after hepatic resection for colorectal metastases. Ann Surg 2005, 241:715-722.

28. Are C, Gonen M, Zazzali K, Dematteo RP, Jarnagin WR, Fong Y, Blumgart LH, D'Angelica M: The impact of margins on outcome after hepatic resection for colorectal metastasis. Ann Surg 2007, 246:295-300.

29. Nuzzo G, Giuliante F, Ardito F, Vellone M, Giovannini I, Federico B, Vecchio FM: Influence of surgical margin on type of recurrence after liver resection for colorectal metastases: a single-center experience. Surgery 2008, 143:384-393.

30. Folprecht G, Gruenberger T, Bechstein WO, Raab HR, Lordick F, Hartmann JT, Lang H, Frilling A, Stoehlmacher J, Weitz J, Konopke R, Stroszczynski C, Liersch T, Ockert D, Herrmann T, Goekkurt E, Parisi F, Köhne $\mathrm{CH}$ : Tumour response and secondary resectability of colorectal liver metastases following neoadjuvant chemotherapy with cetuximab: the CELIM randomised phase 2 trial. Lancet Oncol 2010, 11:38-47.

31. Wakai T, Shirai Y, Sakata J, Valera VA, Korita PV, Akazawa K, Ajioka Y, Hatakeyama K: Appraisal of $1 \mathrm{~cm}$ hepatectomy margins for intrahepatic micrometastases in patients with colorectal carcinoma liver metastasis. Ann Surg Oncol 2008, 15:2472-2481.

32. Wray CJ, Lowy AM, Mathews JB, Park S, Choe KA, Hanto DW, James LE, Soldano DA, Ahmad SA: The significance and clinical factors associated with a subcentimeter resection of colorectal liver metastases. Ann Surg Oncol 2005, 12:374-380.

33. Gold JS, Are C, Kornprat $P$, Jarnagin WR, Gönen M, Fong $Y$, DeMatteo RP, Blumgart LH, D'Angelica M: Increased use of parenchymal-sparing surgery for bilateral liver metastases from colorectal cancer is associated with improved mortality without change in oncologic outcome: trends in treatment over time in 440 patients. Ann Surg 2008, 247:109-117.

34. Abdalla EK, Hicks ME, Vauthey JN: Portal vein embolization: rationale, technique and future prospects. Br J Surg 2001, 88:165-175. 
35. Adam R, Laurent A, Azoulay D, Castaing D, Bismuth H: Two-stage hepatectomy: A planned strategy to treat irresectable liver tumors. Ann Surg 2000, 232:777-785.

36. Nordlinger B, Sorbye H, Glimelius B, Poston GJ, Schlag PM, Rougier P, Bechstein WO, Primrose JN, Walpole ET, Finch-Jones M, Jaeck D, Mirza D, Parks RW, Collette L, Praet M, Bethe U, Van Cutsem E, Scheithauer W, Gruenberger T, EORTC Gastro-Intestinal Tract Cancer Group; Cancer Research UK; Arbeitsgruppe Lebermetastasen und-tumoren in der Chirurgischen Arbeitsgemeinschaft Onkologie (ALM-CAO); Australasian Gastro-Intestinal Trials Group (AGITG); Fédération Francophone de Cancérologie Digestive (FFCD): Perioperative chemotherapy with FOLFOX4 and surgery versus surgery alone for resectable liver metastases from colorectal cancer (EORTC Intergroup trial 40983): a randomised controlled trial. Lancet 2008, 371:1007-1016.

37. Meyerhardt JA, Mayer RJ: Systemic Therapy for colorectal cancer. N Engl J Med 2005, 352:476-487.

38. Leonard GD, Brenner B, Kemeny NE: Neoadjuvant chemotherapy before liver resection for patients with unresectable liver metastasis from colorectal carcinoma. J Clin Oncol 2005, 23:2038-2048.

39. Scheele J, Stang R, Altndorf-Hofmann A, Paul M: Resection of colorectal liver metastasis. World J Surg 1995, 19:59-71.

\section{Pre-publication history}

The pre-publication history for this paper can be accessed here: http://www.biomedcentral.com/1471-2482/10/27/prepub

doi:10.1186/1471-2482-10-27

Cite this article as: Hayashi et al:: Clinicopathological analysis of recurrence patterns and prognostic factors for survival after hepatectomy for colorectal liver metastasis. BMC Surgery 2010 10:27.

\section{Submit your next manuscript to BioMed Central} and take full advantage of:

- Convenient online submission

- Thorough peer review

- No space constraints or color figure charges

- Immediate publication on acceptance

- Inclusion in PubMed, CAS, Scopus and Google Scholar

- Research which is freely available for redistribution

Submit your manuscript at www.biomedcentral.com/submit
C Biomed Central 